\title{
Perbedaan Prevalensi Alergi pada Anak Obes Dibandingkan dengan Indeks Massa Tubuh Normal
}

Utami Dewi, Cahya Dewi Satria, Endy Paryanto

Bagian Ilmu Kesehatan anak Fakultas Kedokteran Universitas Gadjah Mada (UGM)/ RSUP Dr. Sardjito, Yogyakarta

Latar belakang. Peningkatan prevalensi obesitas dan alergi merupakan dua masalah kesehatan yang penting. Kelebihan berat badan maupun obesitas merupakan faktor risiko potensial terjadi manifestasi penyakit alergi yang berat.

Tujuan. Mengetahui perbedaan prevalensi alergi dan mendeskripsikan faktor risiko alergi pada anak obes dan IMT normal.

Metode. Kami melakukan penelitian potong lintang pada 45 orang anak obes dan 45 anak non obes antara Februari-Maret 2013. Data yang diperoleh merupakan data primer. Digunakan analisis dengan uji statistik kategorikal menggunakan uji chi-square untuk mengetahui perbedaan prevalensi alergi pada kelompok subyek obes dan kelompok indeks massa tubuh normal.

Hasil. Tidak ada perbedaan bermakna kejadian alergi pada kelompok anak obes maupun IMT normal $(\mathrm{p}=1,000)$.

Kesimpulan. Tidak ada perbedaan prevalensi dan profil faktor risiko alergi pada populasi anak obes maupun IMT normal.

Sari Pediatri 2017;18(6):468-73

Kata kunci: alergi, prevalensi, obes

\section{The Difference of Allergic Prevalence of Obese and Non Obese Children}

Utami Dewi, Cahya Dewi Satria, Endy Paryanto

Background. Obesity and allergy are two increasingly important population health issues. Excess weight and obesity are potential risk factors of severe manifestation of allergic disease.

Objective. To determine the alergic prevalenceand the risk factor in children with obesity compared with normal body mass index (BMI).

Methods. We perform cross sectional study involved 45 obese and 45 non obese children in Februari-Maret 2013. Statistical analysis by chi-square test.

Allergy was defined as clinical manifestation or history of allergic disease confirmed by positif result of skin prick test. The cut-off for defining a positive reaction to an alergen of skin prick test was wheal size of $3 \mathrm{~mm}$ or more

Results. There is no difference in allergy prevalence among school children with obesity compared with those who were non obese $(\mathrm{P}=1,000)$.

Conclusion. There is no difference in allergy prevalence and risk factors among school children with obesity compared with those who were non obese. Sari Pediatri 2017;18(6):468-73

Keyword: allergy, prevalence, obesity

Alamat korespondensi: dr. Utami Dewi, dr. Cahya Dewi Satria, M.Kes, Sp.A. Bagian Ilmu Kesehatan Anak, Fakultas Kedokteran Universitas Gadjah Mada/RSUP Dr. Sardjito Yogyakarta. E-mail: utamidewidr@yahoo.com 


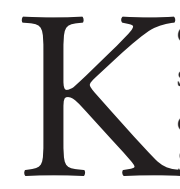

ejadian obesitas dan alergi dilaporkan semakin meningkat. Prevalensi obesitas di Medan, Padang, Palembang, Jakarta, Denpasar dan Manado sekitar 1 Daerah Khusus Ibukota Jakarta, prevalensi obesitas pada umur 6-12 tahun (14\%), anak remaja 12-18 dan 17-18 berturut-turut 6,2\% dan 11,4\%. ${ }^{1}$ Laporan dari Amerika Serikat dan Indonesia menunjukkan adanya peningkatan prevalensi atopi pada anak obes. ${ }^{2-4}$ Pengamatan selama7 tahun pada anak-anak di Swedia menunjukkan peningkatan indeks massa tubuh (IMT) sehingga meningkatkan risiko kejadian alergi tanpa dipengaruhi riwayat alergi keluarga. ${ }^{5}$ Penelitian di Ghana menunjukkan tidak ada perbedaan kejadian atopi antara anak obes maupun anak dengan IMT normal. ${ }^{6}$ Schacter ${ }^{7}$ melaporkan tidak ada perbedaan risiko mengi pada anak obes di Australia.

Obesitas diduga berperan memperberat terjadinya reaksi alergi. Jaringan adiposa pada anak obes akan menimbulkan suatu kondisi pro inflamasi. Jaringan adipose anak obes akan mengekspresikan sejumlah molekul antara lain tumour necrosis factor alpha (TNF- $\alpha$ ), interleukin-6 (IL-6) dan leptin. Peningkatan TNF $\alpha$ dihubungkan dengan peningkatan produksi sitokin limfosit T helper 2 (Th2) seperti interleukin-4 dan interleukin-5 sebagai sinyal awal pengaktifan sistem imun pada atopi. ${ }^{8}$ Leptin memiliki struktur homolog dengan sitokin rantai heliks panjang, seperti IL-6 dan telah diketahui mengatur proliferasi dan aktivasisel T.?

Tujuan penelitian untuk prevalensi alergi pada anak obes lebih tinggi dibanding anak dengan indeks massa tubuh normal.

\section{Metode}

Penelitian dilakukan di Sekolah Dasar di kotamadya di wilayah Yogyakarta selama bulan Februari-Maret 2013.Kriteria inklusi adalah anak Sekolah Dasar dengan usia 8-12 tahun; memiliki indeks masa tubuh (IMT) $\mathrm{P}>95$ dan menyetujui dan menandatangani proxy consent, sedangkan kontrol memiliki IMT $(25 \%<\mathrm{z}<85 \%)$. Subjek dieksklusi bila menderita penyakit imunodefisiensi yang diketahui, misal keganasan, sedang mendapat terapi antihistamin 1 minggu terakhir, dan pasien yang mendapat terapi imunosupresan.
Besar sampel dihitung menggunakan rumus perkiraan untuk penelitian potong lintang dengan melakukan estimasi untuk interval kepercayaan risiko relatif dengan tingkat kemaknaan $\alpha=95 \%(Z \alpha=1,96)$, toleransi estimasi (presisi absolut yang diinginkan $(\mathrm{d}=0,1)$. Estimasi beda proporsi anak obes dengan atopi sebesar 61,9\%. ${ }^{4}$ Besar sampel sejumlah 90 subyek terdiri atas 45 siswa dan siswi sekolah dasar dengan obesitas dan 45 dengan indeks massa tubuh normal.

Dinyatakan alergi apabila ditemukan sedikitnya satu manifestasi klinis pada saat pemeriksaan atau adanya riwayat manifestasi klinis alergi serta hasil pemeriksaan uji cukit kulit positif (ditunjukkan dengan indurasi $>3 \mathrm{~mm}$ ). Variabel lain yang dicatat adalah riwayat cara persalinan, jumlah saudara kandung, riwayat pemberian ASI serta pengukuran skor alergi menggunakan kartu deteksi dini alergi

Penelitian dilakukan setelah mendapatkan persetujuan dari Komite Etik Penelitian Kedokteran dan Kesehatan Fakultas Kedokteran Universitas Gadjah Mada nomer KE/FK/136/EC. Analisis data dilakukan dengan menggunakan program statistik SPSS-forWindow versi 17. Data dipresentasikan sebagai uji statistik kategorikal menggunakan uji chi-square dengan interval kepercayaan 95\% (IK 95\%).

\section{Hasil}

Karakteristik subyek penelitian antara populasi anak obes maupun IMT normal homogen (Tabel 1). Hasil uji chi square didapatkan tidak ada perbedaan bermakna kejadian alergi pada kelompok anak obes maupun IMT normal $(\mathrm{p}=1,000)$ (Tabel 2).

Profil faktor risiko yang dihubungkan terhadap kejadian alergi tidak berbeda pada kelompok anak obes maupun IMT normal (Tabel 3). Hasil uji cukit kulit menunjukan kelompok anak obes cenderung mengalami alergi terhadap alergen hirupan sedangkan kontrol menunjukkan hasil uji cukit kulit positif terhadap alergen makanan maupun hirupan (Tabel 4).

\section{Pembahasan}

Kami tidak mendapatkan perbedaan antara kejadian alergi pada kelompok anak obes maupun IMT normal. Hal ini serupa dengan penelitian 1482 anak usia sekolah di Ghana yang melaporkan tidak ada hubungan antara 
Tabel 1. Karakteristik dasar subyek penelitian

\begin{tabular}{lcc}
\hline & Obes & Non obes \\
\hline Jenis kelamin (\%) & & \\
Laki-laki & $25(28)$ & $21(23)$ \\
Perempuan & $20(22)$ & $24(27)$ \\
Usia (\%, tahun) & & \\
$8-<10$ & $12(12)$ & $11(12)$ \\
10-12 & $33(37)$ & $34(38)$ \\
Pendidikan ayah (\%) & & \\
SMP & $1(1)$ & $1(1)$ \\
SMU & $5(5)$ & $5(5)$ \\
Diploma & $9(10)$ & $7(8)$ \\
S1 & $25(28)$ & $26(29)$ \\
S2 & $5(5)$ & $6(7)$ \\
Pendidikan ibu (\%) & & \\
SMP & 0 & 0 \\
SMU & $8(8,89)$ & $12(13)$ \\
Diploma & $12(13)$ & $5(5)$ \\
S1 & $21(23)$ & $27(30)$ \\
S2 & $4(4)$ & $1(1)$ \\
Status sosial ekonomi (\%), rupiah & & \\
Penghasilan $<2.500 .000,-$ & $15(17)$ & $18(20)$ \\
Penghasilan 2.500.000,- - 5.000.000,- & $15(17)$ & $15(17)$ \\
Penghasilan > 25.000.000,- & $15(17$ & $12(13)$ \\
\hline
\end{tabular}

Tabel 2. Hasil pemeriksaan alergi

\begin{tabular}{lccc}
\hline Hasil pemeriksaan alergi & Obes & IMT normal & $\mathrm{p}$ \\
\hline Positif & 19 & 14 & $1,000^{*}$ \\
Negatif & 26 & 31 & \\
\hline
\end{tabular}

Tabel 3. Karakteristik subyek berdasarkan variabel luar

\begin{tabular}{llcc}
\hline Variabel luar & & Obes $(\mathrm{n}=19)$ & IMT normal $(\mathrm{n}=14)$ \\
\hline Persalinan & Pervaginam & 14 & 14 \\
\multirow{3}{*}{ Siblings } & Bedah sesar & 5 & 0 \\
\multirow{3}{*}{ Pemberian ASI } & $<3$ & 9 & 6 \\
& $\geq 3$ & 10 & $8)$ \\
\multirow{3}{*}{ Skor deteksi dini alergi } & ASI eksklusif & 12 & 7 \\
& Tidak & 7 & 7 \\
& Tinggi & 2 & 0 \\
& Sedang & 4 & 5 \\
& Rendah & 13 & 9 \\
\hline
\end{tabular}

tingginya indeks massa tubuh terhadap kejadian atopi. Namun begitu, pada berat badan kurang berhubungan terbalik dengan atopi. ${ }^{6}$ Demikian pula penelitian Ross ${ }^{10}$ tidak ada perbedaan kejadian asma pada populasi obes dan non obes.
Hubungan obesitas dengan alergi dilaporkan dalam penelitian Visness $\mathrm{dkk}^{2}$ mendapatkan OR IgE total 1,40 (1,19-1,66), OR IgE makanan 1,61 $(1,30-2,98)$ dan OR IgE susu sapi 1,56 (1,20-2,03). Apandi ${ }^{4}$ melaporkan adanya hubungan obesitas, atopi, 
Utami Dewi dkk: Perbedaan prevalensi alergi anak obes dibandingkan dengan IMT normal

Tabel 4. Hasil pemeriksaan uji cukit kulit

\begin{tabular}{|c|c|c|c|c|c|}
\hline Alergen makanan & Obes (\%) & IMT normal (\%) & $\begin{array}{l}\text { Alergen } \\
\text { hirupan }\end{array}$ & Obes (\%) & IMT normal (\%) \\
\hline Terigu & 0 & 0 & Debu & $6(13)$ & $2(4)$ \\
\hline Kuning telur & 0 & $1(2)$ & D. Pteronyssimus & $9(20)$ & $6(13)$ \\
\hline Putih telur & 0 & $2(4)$ & Bulu kucing & $7(15)$ & $2(4)$ \\
\hline Daging ayam & 0 & $1(2)$ & Bulu anjing & $1(2)$ & $5(20)$ \\
\hline Susu sapi & 0 & 0 & B. Germanica & $7(16)$ & $4(9)$ \\
\hline Kedelai & 0 & $1(2)$ & Serpihan kulit & 0 & $4(9)$ \\
\hline Kacang tanah & 0 & $1(2)$ & D. Farinae & $10(22)$ & $8(18)$ \\
\hline Beras & 0 & 0 & & & \\
\hline Tongkol & 0 & $1(2)$ & & & \\
\hline Udang & $2(4)$ & $1(2)$ & & & \\
\hline Kerang & 0 & $1(2)$ & & & \\
\hline Kepiting & $5(11)$ & $3(7)$ & & & \\
\hline Coklat & $1(2)$ & 0 & & & \\
\hline
\end{tabular}

dan riwayat keluarga. Silverberg ${ }^{3}$ melaporkan OR dermatitis 2,64 (1,13-6,18) untuk usia 2,5-5 tahun dan OR 3,4 $(1,34-8,63)$ usia di atas 5 tahun. Silva $\mathrm{dkk}^{11}$ melaporkan OR penyakit atopi $1,7(1,7-5,03)$. Magnusson dkk melaporkan OR kejadian asma 2,48 $(1,4-4,38)$. Mai dkk ${ }^{12}$ melaporkan OR kejadian mengi 1,7 (1,0-2,5). dan Schachter $\mathrm{dkk}^{7}$ melaporkan OR kejadian atopi $1,26(1,01-1,56)$. von Mutius $\mathrm{dkk}^{13}$ melaporkan peningkatan IMT berkaitan dengan peningkatan kejadian asma, (OR 1,77, IK 95\%, 1,442,19) untuk kuartil IMT terendah-tertinggi.

Tidak terdapat perbedaan prevalensi kejadian alergi antara anak yang dilahirkan pervaginam maupun dengan persalinan bedah sesar. Hal ini berbeda dengan penelitian kohort retrospektif pada anak usia 3-10 tahun yang menunjukkan persalinan dengan bedah sesar meningkatkan risiko rhinitis alergi, asma; hubungan positif terbatas pada anak perempuan. ${ }^{14}$ Penelitian kohort prospektif oleh Papathoma, ${ }^{15}$ pada anak sejak lahir-usia 36 bulan,persalinan bedah sesar $(50,8 \%)$ meningkatkan risiko alergi. Anak dengan minimal salah satu orang tua alergi yang dilahirkan melalui bedah sesar memiliki risiko alergi lebih besar dibanding lahir per vaginam.

Dalam penelitian kami tidak terdapat perbedaan prevalensi kejadian alergi antara anak yang memiliki saudara $<3$ maupun $\geq 3$ orang. Penelitian oleh Ball ${ }^{16}$ pada anak menunjukkan bahwa kehadiran $\geq 1$ orang saudara kandung di rumah melindungi terjadinya asma. Hasil penelitian phase three of the international study of asthma and allergic in childhood (ISAAC) ${ }^{17}$ pada anak usia 6-7 tahun dan usia 13-14 tahun menunjukkan bahwa memiliki $\geq 3$ orang saudara menurunkan risiko rhinitis alergi (usia 6-7 tahun) dan asma (usia 13-14 tahun) dibandingkan anak tunggal. European community respiratory health study II (ECRHS II) melaporkan insidensi rhinitis alergi menurun dengan bertambahnya jumlah saudara kandung. ${ }^{18,19}$

Kami mendapatkan pemberian ASI eksklusif relatif sama antara kelompok obes maupun IMT normal. Pemberian ASI terbukti melindungi terhadap penyakit infeksi, obesitas, dan beberapa penyakit kronik sehingga WHO merekomendasikan pemberian ASI selama 6 bulan. Penelitian ISSAC menyatakan pemberian ASI melindungi terjadinya mengi non atopi. ${ }^{20}$

Penelitian kohort prospektif menunjukkan pada usia 4 tahun tidak mendapat ASI meningkatkan risiko mengi dibanding mendapat ASI 6 bulan..$^{21}$ Penelitian kohort prospektif di Selandia Baru pada bayi selama 6 tahun menunjukkan bahwa masing-masing bulan pemberian ASI eksklusif menurunkan kejadian asma pada usia 2, 3, 4, 5, 6 tahun. Masing-masing bulan pemberian ASI eksklusif menurunkan kejadian asma $17 \%, 12 \%, 11 \%, 12 \%$, dan $9 \%$ berturut-turut pada umur 2, 3, 4, dan 5 tahun. ${ }^{22,23}$

Tidak terdapat perbedaan prevalensi kejadian alergi antara anak yang memiliki skor sedang-tinggi maupun rendah pada penilaian skor deteksi dini alergi. Atopi bersifat diturunkan, risiko seorang anak mengalami alergi yang diperantari IgE sekitar 40\%-60\% bila kedua orang tua atopi. Risiko 5\%-10\% bila kedua orang tua tidak atopi. Pada anak risiko atopi tinggi, 
Utami Dewi dkk: Perbedaan prevalensi alergi anak obes dibandingkan dengan IMT normal

sensitisasi IgE dan penyakit alergi berkembang pada awal kehidupan. ${ }^{24}$

Kelompok anak obes lebih sering mengalami alergi terhadap alergen hirupan, sedangkan kontrol menunjukkan hasil uji cukit kulit positif terhadap alergen makanan maupun hirupan. Sensitisasi uji cukit kulit terbanyak pada kelompok obes maupun IMT normal terhadap $D$. farinae (20\%). Hal ini serupa dengan penelitian $\mathrm{Li} \mathrm{dkk}^{26}$ yang melaporkan bahwa senstitisasi terbanyak terhadap $D$. pteronyssimus $(50,6-81,4) \%$ dan $D$. farinae $(50,1-82) \%$ pada anak pengidap asma dan rhinitis di empat wilayah di Cina. Paparan alergen domestik merupakan faktor penentu yang kuat terjadinya sensitisasi awal pada anak. ${ }^{20}$ Sensitisasi aeroalergen pada individu atopi dapat menginduksi reaksi inflamasi pada mukosa jalan nafas. Peradangan jalan nafas dihubungkan dengan perubahan hiperesponsifitas jalan nafas, penyempitan aliran udara, gejala hidung, dan pernafasan serta kronisitas penyakit. ${ }^{26}$

\section{Kesimpulan}

Tidak ada perbedaan prevalensi alergi pada populasi anak obes maupun IMT normal.

\section{Daftar pustaka}

1. Sjarif, D. Obesitas pada anak dan remaja. Dalam: Sjarif $\mathrm{D}$, penyunting. Buku ajar nutrisi pediatrik dan penyakit metabolik. Jakarta: Badan Penerbit IDAI; 2012.h.229-44.

2. Visness C, London S, Daniels, J. Association of obesity with IgE levels and allergy symptoms in children and adolescents: results from the national health and nutrition examination survey 2005-2006. J Allergy Clin Immunol 2009;123:1163-9.

3. Silverberg J, Kleiman E, Lev-Tov H. Association between obesity and atopic dermatitis in childhood: a case-control study. J Allergy Clin Immunol 2011;127:1180-6.

4. Apandi P, Setiabudiawan B, Sukadi A. A correlation between obesity with atopy and family history of atopy in children. Pediatr Indones 2012;51:227-33.

5. Magnusson J, Kull I, Mai X. Early childhood overweight and asthma and allergic sensitization at 8 years of age. Pediatrics 2012;129:70-6.

6. Larbi I, Klipstein-Grobusch K, Amoah A. High body mass index is not associated with atopy in schoolchildren living in rural and urban areas of Ghana. BMC. Pub Health 2011; 11:469.
7. Schachter L, Peat J, Salome C. Asthma and atopy in overweight children. Thorax 2003; 58 : 1031-5.

8. Hersoug L, Linneberg A. The link between the epidemics of obesity and allergic diseases: does obesity induce decreased immune tolerance? Allergy 2007;62:1205-13.

9. Beuther D, Scott T, Sutherland E. Obesity and asthma. Am J Resp Crit Care Med 2006;174:112-9.

10. Ross K, Hart M, Storfer-Isser A. Obesity and obesity related co-morbidities in a referral population of children with asthma. Pediatr. Pulmonol 2009;44:877-84.

11. Silva M, Ribeiro M, Carvalho F. Atopic disease and body mass index. Allergol Immunopathol (Madr) 2007;35:130-5.

12. Mai X, Nilsson L, Axelson O. High body mass index, asthma and allergy in Swedish schoolchildren participating in the International Study of Asthma and Allergies in Childhood: Phase II 2007;92:1144-8.

13. von Mutius E, Schwartz J, Neas L . Relation of body mass index to asthma and atopy in children: the National Health and Nutrition Examination Study III. Thorax 2001; 56 : 835-838

14. Renz-Polster H, David M, Buist A. Caesarean section delivery and the risk of allergic disorders in childhood. Clin Exp Allergy 2005;35:1466-72.

15. Papathoma E, Triga M Fouzas S. Cesarean section delivery and development of food allergy and atopic dermatitis in early childhood. Pediatr Allergy Immunol 2016;27:419-24.

16. Ball T, Castro-Rodriguez J, Griffith K. Siblings, day-care attendance, and the risk of asthma and wheezing during childhood. N Engl J Med 2000;343:538-43.

17. Strachan D, Ait-Khaled N, Foliaki S. Siblings, asthma, rhinoconjunctivitis and eczema: a worldwide perspective from the International Study of Asthma and Allergies in Childhood. Clin Exp Allergy 2015;45:126-36.

18. Matheson M, Dharmage S, Abramson M. Early-life risk factors and incidence of rhinitis: Results from the European Community Respiratory Health Study-an international population-based cohort study. J Allergy Clin Immunol 2011; 128:816-23.

19. Ramsey A, Deane P. Early-life risk factors and allergic rhinitis: comparing European and US data. Didapat dari: URL: http://www.anafylaxis.nl/PDF/Early\%20life\% 20risk\%20factors\%20AR\%20EU\%20vs\%20USA.pdf.

20. Van der Poel LA. Paediatric Allergy in Review. Paediatrics and Child Health 2012;22:259-63.

21. Sonnenschein-Van der Voort A, Jaddoe V, van der Valk R. Duration and exclusiveness of breastfeeding and childhood asthma-related symptoms. Eur Respir J 2012;39:81-9.

22. Silvers K, Frampton C, Wickens K. Breastfeeding protects againts current asthma up to 6 years of age. J Pediatr 2012; $160: 991-6$ 
23. Dick S, Friend A, Dynes K. A systematic review of associations between environmental exposures and development of asthma in children aged up to 9 years. Didapat dari: URL:http:// bmjopen.bmj.com/content/4/11/e006554.full.pdf+html.

24. Johansson S, Hourihane J, Bousquet J. A revised nomenclature for allergy. An EAACI position statement from the EAACI nomenclature task force. Allergy 2001;56:813-24.
25. Liem J, Huq S, Kozyrskyj A, Becker A. Should younger siblings of peanut-allergic children be assessed by an allergist before being fed peanut? Allergy, Asthma and Clinical Immunology 2008; 4:144-9.

26. Li J, Sun B, Huang Y. A multicentre study assessing the prevalence of sensitizations in patients with asthma and/or rhinitis in China. Allergy 2009; 64:1083-92. 